\title{
Streptococcus iniae: An Unusual Important Pathogen Fish in Brazil
}

Lucienne Garcia Pretto-Giordano ${ }^{1 *}$, Josiane Aniele Scarpassa ${ }^{2}$, André Rocha Barbosa ${ }^{2}$, Carla Suzuki Altrão², Carolina Galdino Gumiero Ribeiro ${ }^{1}$ and Laurival Antônio Vilas-Boas ${ }^{3}$

${ }^{1}$ Departamento de Medicina Veterinária Preventiva, Universidade Estadual de Londrina, CP 10.011, CEP 86057.970, Londrina/PR, Brazil

${ }^{2}$ Programa de Pós-graduação em Ciências Biológicas, Universidade Estadual de Londrina, CP 10.011, CEP 86057.970, Londrina/PR, Brazil

${ }^{3}$ Departamento de Biologia Geral, Universidade Estadual de Londrina, CP 10.011, CEP 86057.970, Londrina/PR, Brazil

\begin{abstract}
The current paper contains a report on the isolation of Streptococcus iniae in Nile tilapia (Oreochromis niloticus) in Brazil and South America. S. iniae is an important pathogen often associated with significant losses in fish production. It is also known for causing invasive infections in humans. An outbreak of infections characterized by exophthalmos, erratic swimming, ascites and melanosis occurred in intensive fish farming. Samples of kidney, brain and liver of the fish seeded into the culture medium yielded beta-hemolytic, gram-positive cocci isolate from the colonies. The partial sequencing of the $16 \mathrm{~S}$ ribosomal gene was performed to identify the isolate. The sequence obtained showed $99 \%$ identity to 16 S sequences of $S$. iniae present in the Genbank. A phylogenetic analysis was accomplished to confirm the species. Although $S$. iniae is frequently present in almost all continents, this work disclosed the second case of isolation of this pathogen in farmed fish both in Brazil and South America.
\end{abstract}

The tilapia culture is one of the fastest growing sectors in the food production industry worldwide. Intensive breeding is one of the most used systems for the species growth with high stocking rates. High feeding rates usually result in changes in the water quality and animal stress, enabling the incidence of infectious diseases [1-3]. The available literature reports that Streptococcus iniae and Streptococcus agalactiae constitute the primary cause of streptococcosis in intensive fish farming. S. iniae is an important pathogen in aquaculture, which may cause considerable economic losses and infect different species of marine and freshwater fish. Furthermore, it is an emerging zoonotic pathogen $[4,5]$.

The first isolation of S. iniae occurred in the 1970s from skin lesions on dolphins (Inia geoffrensis). Then, it was subsequently identified in fish in North America, Middle East, Asia-Pacific region and Europe [4,6-8]. There are several strepococcosis reports in the Nile tilapia (Oreochromis niloticus) in Brazil, always associated with $S$. agalactiae [9-12]. Neverteless, only in 2012 Figueiredo et al. [13], described a meningoencephalitis outbreak of $S$. iniae in tilapia, the only case reported in South America.

The most common disease symptoms induced by $S$. agalactiae and S.iniae in fish are similar. They include exophthalmia, ascites, erratic swimming, lethargy, melanoseis, meningoencephalitis, septicemia and high mortality $[4,10,12,14]$. The objective of this study was to report the second case of isolation and molecular identification of $S$. iniae in the Brazilian Nile tilapia (O. niloticus).

An outbreak of the Nile tilapia (O. niloticus) mortality occurred in an intensive fish farming located in the basin of the Paranapanema River. Five fish with an average weight of $300 \mathrm{~g}$ exhibited clinical signs of exophthalmia, ascites, erratic swimming, lethargy and melanosis. Such five fish were sent alive in bags with water from the site and oxygen to the laboratory of Veterinary Microbiology and Infectious Diseases of the State University of Londrina. The fish were anesthetized with benzocaine solution, alcohol and water at a ratio of $1 \mathrm{~g} / 10 \mathrm{ml} / 10 \mathrm{~L}$ [15], respectively, and submitted to autopsy.

Samples of kidney, brain and liver were collected and immediately inoculated onto Columbia agar (Difco Laboratories, Sparks, MD) supplemented with $5 \%$ defibrinated sheep blood, and incubated at $30^{\circ} \mathrm{C}$ for 48 hours under aeroçhilic conditions. The obtained colonies were submitted to Gram stain, catalase, esculin and serology tests using the Slidex Strepto kit (BioMérieux-France).

The isolated colonies underwent genomic DNA extraction as described by [16]. For molecular analyses, the strategy of partial amplification of the 16S rRNA region with the FD1 and RD1 primers was used, following the protocol described by the authors [17]. The amplification product was purified using the WizardSV Gel and PCR Clean-Up System (Promega) and sequenced by the Sanger method.

For the identification of the bacterial species, the obtained sequences were compared to the sequences deposited in the GenBank [18] using the Blastn program. In addition to the direct comparison, we performed a phylogenetic study aligning the selected sequences using the ClustalW algorithm exporting the sequences in the Mega 6 program [19]. Accordingly, nine partial sequences of the $16 \mathrm{~S}$ rRNA gene isolates of S. iniae deposited in the GenBank until February 2015, which corresponded to the region delimited by the primers, were retrieved from the databases. Furthermore, we utilized two sequences of $S$. agalactiae besides another of Streptococcus parauberis that was used as a tree root. All sequences of $S$. iniae utilized were isolates from fish: three from Brazil [13], one from Taiwan (AY762259.1), one from Indonesia (KM209199.1), one from China (JQ990158.1) one from Israel (AF335573), one from Iran (FJ870987) and one from North America (NR025148.1) ATCC29178, besides the isolate obtained in this work. A phylogenetic tree was constructed using the neighborjoining bootstrap method with 1,000 replicates.

Most of the isolated colonies were punctiform, gray, Gram-

*Corresponding author: Lucienne Garcia Pretto-Giordano, Departamento de Medicina Veterinária Preventiva, Universidade Estadual de Londrina, CP 10.011, CEP 86057.970, Londrina/PR, Brazil, E-mail: Igiordano@uel.br

Received May 27, 2015; Accepted June 11, 2015; Published September 15 2015

Citation: Pretto-Giordano LG, Scarpassa JA, Barbosa AR, Altrão CS, Ribeiro CGG, et al. (2015) Streptococcus iniae: An Unusual Important Pathogen Fish in Brazil. J Aquac Res Development 6: 363. doi:10.4172/2155-9546.1000363

Copyright: ( 2015 Pretto-Giordano LG, et al. This is an open-access article distributed under the terms of the Creative Commons Attribution License, which permits unrestricted use, distribution, and reproduction in any medium, provided the original author and source are credited. 
Citation: Pretto-Giordano LG, Scarpassa JA, Barbosa AR, Altrão CS, Ribeiro CGG, et al. (2015) Streptococcus iniae: An Unusual Important Pathogen Fish in Brazil. J Aquac Res Development 6: 363. doi:10.4172/2155-9546.1000363

Page 2 of 3

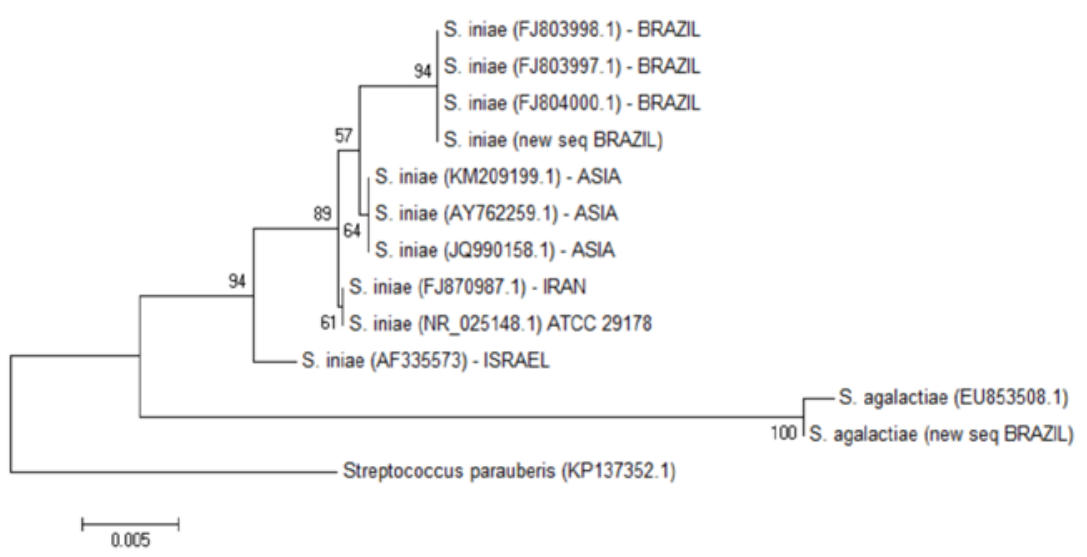

Figure 1: Phylogenetic tree constructed using the neighbor-joining, showing the distribution of different isolates of $S$. iniaeand $S$. agalactiae, based on the partial sequence of the $16 \mathrm{~S}$ gene. The tree was rooted by $S$. parauberis(outgroup). Bootstrap method with 1,000 replicates.

positive cocci, catalase-negative and esculin-negative. Serology allowed the classification under Lancefield group $\mathrm{B}$, and identification as $S$. agalactiae (Data not shown). Nevertheless, one liver isolate of a fish presented $\beta$-hemolytic colonies and was not classified under any of the Lancifield groups. The partial 16S rRNA gene sequence showed $99 \%$ identity to the partial sequences of the $16 \mathrm{~S}$ gene from the seven isolates of $S$. iniae with $100 \%$ coverage.

The analysis of the yielded phylogenetic tree indicated that the isolates identified as $S$. iniae were grouped into two clusters Figure 1. We can observe three groups corresponding to the tree root (S. uberis), a defined group composed of $S$. agalactiae and a group composed of the isolates of $S$. iniae. The isolate obtained in this work was grouped into a tree branch along with the three isolates from Brazil [13]. The remaining strains were distributed in the cluster. These results, together with the comparison data to other sequences clearly indicate that the isolate belongs to the $S$. iniae species.

The $S$. iniae strain isolated in this study showed greater genetic similarity to those isolated by Figueiredo et al. [13], when compared to the other strains. However, along with the others, it diverges from the isolates of $S$. agalatiae. The phylogenetic tree shows a clear geographical separation between the groups indicating genetic proximity and specialization of Brazilian isolates. This proximity may indicate that the occurrence of this important pathogen in Brazil is not occasional.

Streptococcosis is a disease that occurs in Brazil causing severe losses to the fish culture industry. Worldwide, S. iniae is described as one of the most important pathogens causing this disease. Currently, $S$. agalactiae is considered the main cause of streptococcosis in Brazilian intensive fish farming while the occurrence of $S$. iniae was reported only once in this country [13]. Although $S$. iniae is frequently reported in other continents, this work presented the second case of isolation of this pathogen in Brazilian and South American fish farming.

The overall results call for more extensive studies of S. iniae aiming to understand the actual distribution of this species in Brazil, its role in streptococcosis, and its diversity and epidemiological significance. These findings also urge the authorities to subsidize recommendations and encourage specific management practices for monitoring fish health and growth.

\section{References}

1. Plumb JA (1997) Infectious diseases of tilapia

2. Shoemaker CA, Evans JJ, Klesius PH (2000) Density and dose: factors affecting mortality of Streptococcus iniae infected tilapia (Oreochomis niloticus). Aquaculture 188: 229-235.

3. Souza GMD, Pretto-Giordano LG, Vilas-Bôas GT, Carvalho TO, SilvaSouza AT, et al. (2015) Microbiological Evaluation of Water and Fillets in the Production Chain of Nile Tilapia (Oreochromis niloticus).

4. Agnew W, Barnes AC (2007) Streptococcus iniae: An aquatic pathogen of global veterinary significance and challenging candidate for reliable vaccination. Veterinary Microbiologic 122: 1-15.

5. Baiano JCF, Barnes AC (2009) Towards control of Streptococcus iniae. Emerging Infectious Diseases 15: 1891-1896

6. Pier GB, Madin SH (1976) Streptococcus iniae sp. nov., a betahemolytic Streptococcus isolated from an Amazon freshwater dolphin, Inia geoffrensis. Int J Systematic Bacteriology 26: 545-553.

7. Aamri F El, Padilla D, Acosta F, Caballero MJ, Roo J, et al. (2010) First report of Streptococcus iniae in red porgy (Pagrus pagrus, L.) J Fish Dis 33: 901-905

8. Anshary H, Kurniawan RA, Sriwulan S, Ramli R, Baxa DV (2014) Isolation and molecular identification of the etiological agents of streptococcosis in Nile tilapia (Oreochromis niloticus) cultured in net cages in Lake Sentani, Papua Indonesia. SpringerPlus 3: 627.

9. Salvador R, Müller EE, Leonhardt JH, Pretto-Giordano LG; Dias JA, et al. (2003) Isolation of Streptococcus spp from nile tilapia (Oreochromis niloticus) and quality of water in hapas nets in North Region of Paraná State, Brazil. Semina 24: 35-42.

10. Salvador R, Müller EE, Leonhardt JH, Pretto-Giordano LG, Dias JA, et al. (2005) Isolation and characterization of Streptococcus spp. group B in Nile tilapia (Oreochromis niloticus) reared in hapas nets and earth nurseries in the northern region of Parana State, Brazil. Ciência Rural 35: 1374-1378.

11. Figueiredo HCP, Carneiro DO, Faria FC, Costa GM (2006) Streptococcus agalactie associated to meningoencefalitis and systemic infection from tilapia (Oreochromis niloticus) in Brazil. Arquivo Brasileiro Medicina Veterinária e Zootecnia 58: 1678-1680.

12. Pretto-Giordano LG, Muller EE, Freitas JC, Silva VG (2010) Evaluation on the pathogenesis of Streptococcus agalactiae in Nile Tilapia (Oreochromis niloticus). Brazilian Archives of Biology and Technology 53: 87-92.

13. Figueiredo HCP, Nobrega Netto L, Leal CAG, Pereira UP, Mian GF (2012) Streptococcus iniae outbreaks in brazilian nile tilapia (Oreochromis niloticus L.) farms. J Microbiol 43.2: 576-580.

14. Bromage ES, Owens L (2002) Infection of barramundi Lates calcarifer with 
Citation: Pretto-Giordano LG, Scarpassa JA, Barbosa AR, Altrão CS, Ribeiro CGG, et al. (2015) Streptococcus iniae: An Unusual Important Pathogen Fish in Brazil. J Aquac Res Development 6: 363. doi:10.4172/2155-9546.1000363

Page 3 of 3

Streptococcus iniae: effects of different routes of exposure. Dis Aquat Organ 52: $199-205$

15. Stoskopf MK (1993) Fish medicine.

16. Ricieto APS, Fazion FAP, Carvalho CD, Vilas-Boas LA, Vilas-Bôas GT (2012) Effect of vegetation on the presence and genetic diversity of Bacillus thuringiensis in soil. Can J Microbiol 59: 28-33.
17. Weisburg WG, Barns SM, Pelletier DA, Lane DJ (1991) 16S ribosomal DNA amplification for phylogenetic study. J Bacteriol 173: 697-703.

18. http://blast.ncbi.nlm.nih.gov/Blast.cgi

19. Tamura K, Peterson D, Peterson N, Stecher G, Nei M, et al. (2011) MEGA5 Molecular Evolutionary Genetics Analysis using Maximum Likelihood, Evolutionary Distance, and Maximum Parsimony Methods. Mol Biol Evol 28: 2731-2739. 